\title{
Polyorchidism: sonographic and magnetic resonance imaging findings
}

\author{
Soner Yalçınkaya, $M D ;^{*}$ Coskun Şahin, $M D ;^{*}$ Ali Feyzullah Şahin, $M D^{+}$ \\ *Department of Urology, Gümüssuyu Military Hospital, İstanbul, Turkey; `Department of Urology, MH Tepecik Research and Education Hospital, İzmir, Turkey
}

Cite as: Can Urol Assoc J 2011;5(5):E84-E86; D0l:10.5489/cuaj.10077

\begin{abstract}
Polyorchidism is a rare anomaly and frequently associated with criptorchidism, inguinal hernia and testicular torsion. It is also reported as increased risk of testicular malignancy. We report a case of 23 year old man with left supernumerary testis in the left hemiscrotum. He presented with painless mass in his left hemiscrotum. Normal physical examination and laboratory tests including spermiogram were examined. Both ultrasound and MRI examinations revealed polyorchidism without malignancy or any other concomitant features. In most cases sonography alone is diagnostic. MRI may provide additional information in complicated cases of polyorchidism. Conservative treatment with sonographic follow-up is the choice of treatment in uncomplicated cases.
\end{abstract}

$\mathrm{P}$ olyorchidism is an anomaly of the genitourinary tract, with almost 200 cases reported in the literature; it refers to the presence of more than two testes. ${ }^{1}$ This congenital anomaly typically causes no impairments, but it is frequently associated with maldescended testis, inguinal hernia and testicular torsion. Reports slso show an increased risk of testicular malignancy in the presence of polyorchidism. ${ }^{2}$ This paper presents a case of polyorchidism without any associated anomaly in a 23-year-old man.

\section{Case report}

A 23-year-old man presented with a painless spherical mass in the left hemiscrotum (Fig. 1). He first noticed this scrotal mass at the age of 11 . The patient had no other medical history and was otherwise asymptomatic. Physical examination and laboratory tests, including a spermiogram, failed to reveal any other pathological finding. Scrotal ultrasonography showed a normal testicular gland measuring $32 \mathrm{~mm}$ in length on the right side. On the left side, two separate glands measuring $28 \mathrm{~mm}$ and $18 \mathrm{~mm}$ in length, with identical echo texture, were noted. All three glands demonstrated a separate epididymis. Further evaluation with magnetic resonance imaging (MRI) confirmed the presence of a super- numerary testis in the left hemiscrotum. All three glands had the identical signal characteristics on $\mathrm{T} 1$ and $\mathrm{T} 2$ weighted images. Following intravenous gadolinium administration, no pathological contrast enhancement within the testes was present (Fig. 2, Fig. 3). On the basis of these imaging findings, a diagnosis of polyorchidism was made. Considering the increased risk of testicular malignancy, the patient was followed 4 times for the first year, 2 times for the second year and annually thereafter.

\section{Discussion}

The exact mechanism for occurence of polyorchidism is still not known. Several theories have been proposed, including peritoneal folding, segmentation of the primitive gonads longitudinal or transverse division of the genital ridge. ${ }^{3}$

In fetal life, at about 6 weeks of gestation, the primordial testis develops from the primitive genital ridge medial to the mesonephric ducts. The primordial testis takes shape and the epididymis with the vas deferens arise from the mesonephric duct at 8 weeks. ${ }^{4}$ On the basis of embryologic development, Leung classified polyorchidism into 4 types. ${ }^{5}$ In type $\mathrm{A}$, the division separates a small part of the genital ridge which does not contact the mesonephric duct. Therefore, the supernumerary testis lacks an epididymis and vas deferens. In type B, the division of the genital ridge occurs in the region where the primordial gonads are attached to the mesonephric ducts and the supernumerary testis has its own epididymis. In type $\mathrm{C}$, the supernumerary testis has its own epididymis and shares the vas deferens with the regular testis in a parallel fashion. In this type of polyorchidism, there is an incomplete longitudinal division of the genital ridge and the proximal portion of the mesonephric duct. In type D, which is the least common, complete longitudinal duplication of the genital ridge and mesonephric duct occurs, with resultant complete duplication of testes, epididymides and vas deferens.

Bergholz and colleagues published a meta-analysis of polyorchidism in 187 cases; 140 cases had histological confirmation. ${ }^{1}$ The median age was 17 years and most patients 


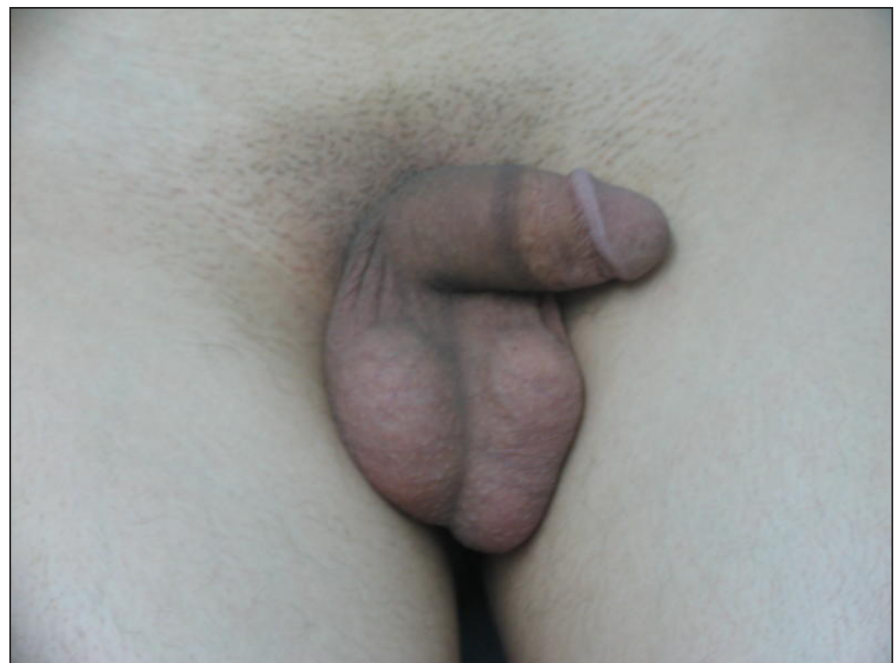

Fig. 1. Macroscopic vision of the supernumerary testis.

were young adults with age range of $11\left(25^{\text {th }}\right.$ percentile) to $25\left(75^{\text {th }}\right.$ percentile) years. In most cases, a single and generally left-sided supernumerary testis was present. A painless scrotal mass, which the patient noted for a long time, was the complaint in uncomplicated cases. The most common location for the supernumerary testis was within the scrotum. However, it may be presented with maldescended testis or it may itself be maldescended with two testicles in the scrotum.

Associated anomalies with polyorchidism includes inguinal hernia in $24 \%$, cryptorchidism in $22 \%$ and testicular torsion $15 \%$ of cases. ${ }^{1}$ Amodio and colleagues reported a case of triorchidism with co-existant microlithiasis, ${ }^{7}$ but to the best of our knowledge, there has not been a reported increase in the incidence of microlithiasis and polyorchidism. Polyorchidism may also be discovered as an incidental finding in association with hydrocele, epididymitis, varicocele, infertility, retractile testes and hypospadias. ${ }^{8}$ Reports in the literature also show an increased risk of testicular malignancy $(6.4 \%)$ in the presence of polyorchidism. ${ }^{1,2}$ Malignant transformation may occur regardless of the location of the supernumerary testis. Most commonly reported neoplasms are embryonal carcinoma, germ cell tumor and seminomas. ${ }^{1,2,9}$ Extratesticular rhabdomyosarcoma and adenoma of rete testis arising in a supernumerary testicle have also been noted. ${ }^{1}$

The sonographic appearance of polyorchidism is a scrotal mass that has an echo pattern identical to that of the ipsilateral testicle. ${ }^{10}$ Colour Doppler sonography shows flow characteristics similar to those of the ipsilateral testis. On MRI, a round or oval shaped structure showing typical signal characteristics of testicles, with homogeneous intermediate signal intensity on $\mathrm{T} 1$ weighted and high signal intensity on T2 weighted images was found. ${ }^{11}$ In uncomplicated cases of polyorchidism, an MRI does not provide any additional data to that given by sonography, but only plays a confirmative role. However,

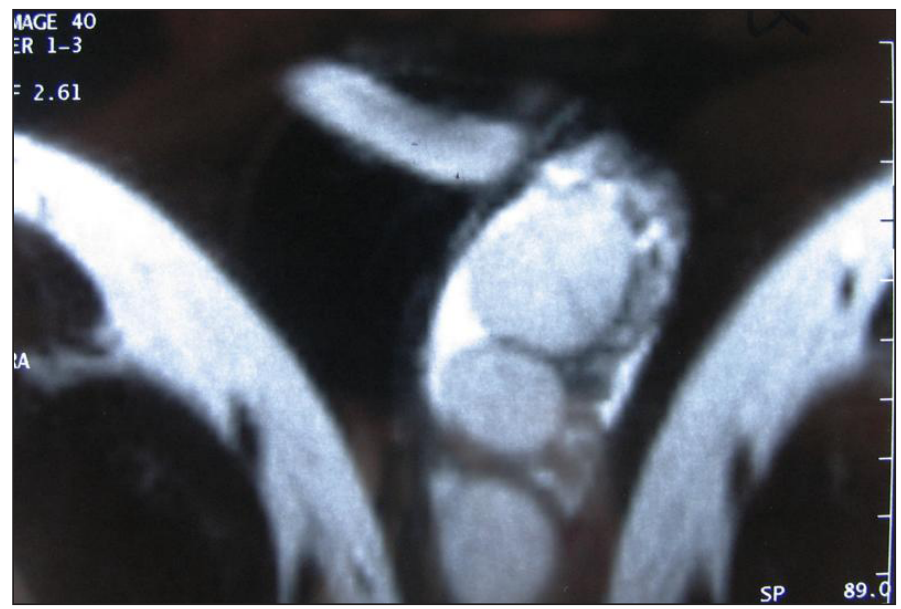

Fig. 2. Magnetic resonance imaging findings of the supernumerary testis.

MRI plays an important role in complicated cases, such as those associated with cryptorchidism and tumours.

Splenogonadal fusion is a rare congenital anomaly that may sonographically resemble polyorchidism. ${ }^{11,12}$ In this entity spleen, gonad, epididymis and vas deferens are fused. Sonography reveals a mass with the testicle of similar echogenicity and it may mimic the appearance of polyorchidism. When splenogonadal fusion is suspected, a technetium sulfur colloid scan should be performed to confirm the presence of ectopic splenic tissue. ${ }^{11}$

In the setting of an uncomplicated polyorchidism, the current treatment is conservative, including a close sonographic observation, with a biopsy of the supernumerary testicle for diagnosis or follow-up being unnecessary. ${ }^{3,6} \mathrm{On}$ the other hand, in the presence of coexisting conditions, such as crytorchidism, torsion or malignancy, surgical treatment is indicated.

\section{Conclusion}

Polyorchidism is a rare congenital anomaly with characteristic sonographic features. In most cases, sonography alone is diagnostic. An MRI may provide additional information in complicated cases of polyorchidism. Conservative treat-

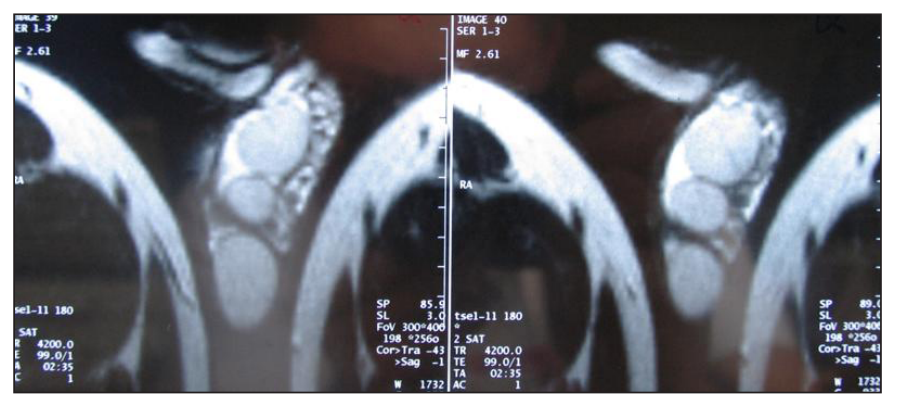

Fig. 3. Separate epididymis of the supernumerary testis was confirmed by magnetic resonance imaging. 
Yalçınkaya et al.

ment with sonographic follow-up is the choice of treatment in uncomplicated cases.

\section{Competıng interests: None declared.}

This paper has been peer-reviewed.

\section{References}

1. Bergholz R, Wenke K. Polyorcihidism: a meta-analysis. J Urol 2009;182:2422-7.

2. Kulkarni JN, Bhansali MS, Tongaonkar HB, et al. Carcinoma in the third testis in a case of polyorchidism and persistent müllerian structure syndrome. Eur Urol 1992;22:174-6.

3. Singer BR, Donaldson JG, Jackson DS. Polyorchidism: Functional classification and management strategy. Urology 1992:39:384-8
4. Wolf B, Youngson GG. Polyorchidism. Pediatr Surg Int 1998;13:65-6.

5. Leung AK. Polyorchidism. Am Fam Physician 1988;38:153-6.

6. Berger AP, Steiner H, Lorenz H, et al. Occurence of polyorchidism in a young man. Urology 2002;60:911-2.

7. Amodio JB, Maybody M, Slowotsky C, et al. Polyorchidism: Report of 3 cases and review of the literature. I Ultrasound Med 2004;23:951-7.

8. Jorion JL, Wese $\mathrm{FX}$, Hennebert $\mathrm{P}$, et al. Polyorchidism: report of three cases and further embryological considerations. Eur Urol 1990;17:90-2.

9. Grechi G, Zampi GC, Selli C, et al. Polyorchidism and seminoma in a child. J Urol 1980;123:291-2.

10. Chung TJ, Yao WJ. Sonographic features of polyorchidism. J Clin Ultrasound 2002;30:106-8.

11. Akbar S, Sayyed T, Jafri S, et al. Multimodality imaging of paratesticular neoplasms and their rare mimics. Radiographics 2003;23:1461-76.

12. Cirillo R, Coley B, Binkovitz L, et al. Sonographic findings in splenogonadal fusion. Pediatr Radiol 1999;29:73-5

Correspondence: Dr. Ali Feyzullah Şahin, Department of Urology, MH Tepecik Research and Education Hospital, Izmir, Turkey; uroali@yahoo.com 